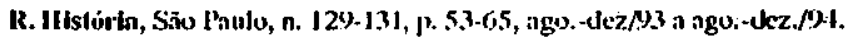

\title{
O NEGRO EM SALVADOR: OS ATALHOS RACIAIS *
}

\author{
Jeferson Bacelar **
}

RESUMO: Ó autor tem como dijetu de esludo o negro na cichde de Salvadur desde as primeiras décadas do sćxulu XX nté @ clias aluais. Prioriza as malizes regionais ke preconceitu e da tiscrimi-

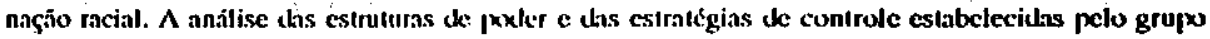
doninante se apresentam como direlrizes para us cslidus solore o racismo.

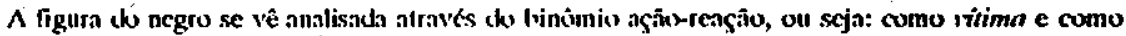

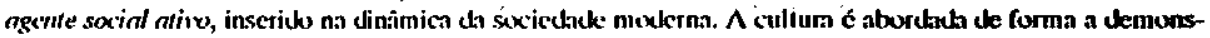

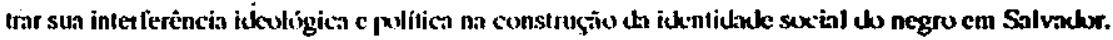

PALAVRAS-CIIAVI: carnaval, racismo, controle sixial, identidade, resistência.

\section{Introduçăo}

A presença do negro na socicdade brasileira d́ mareada pela exı́rema privaçio das formas elementares de existência para grandes contingentes, desigualdade no mundo do traballo e no consumo, bem como a presença constante do preconceito e discriminação racial. Porém, conforme iremos enfatizar, enlocando a cidade de Salvador, esses processos gerais sáo matizados por nuances e diferenças regionatis, denoladoras do negro como porlador de várias lisistórias na sociedacle brasileira.

Pressupomos, por outro lado, quie a sua condiçĩo his tórica de dominado no Brasil, implicita a necessidade de um conhecimento das estruturas de poder e estralégias de controle estabelecidas pelos grupos dominantes na específica e peculiar socicdade regional. E quem domina dá o tom e caráler da ordem social eslabelecida.

Entrelanto, o negro não é "vítima indelesa" de um clamoroso destino hislórico, mas um agenle alivo nas formulaçōes societírias. Se, por um lado, de torma mais rara, $\mathrm{cm}$ insınles c circunslancias as suas formas de resistência são abarcadas pelo binômio açīo-reaçĩo, por outrọ, de forma contínua,

- Este iratnlho foi apresentadu originalmente na Universidade da Flórida, em Gainesville, na 25* Conferência "Błack Brazil".

** Mestre em Antropolugia pxla IIniversidade lederal da Bahia. 
BAC.ELAR, Jeferson .O negro em Salvador; os ntalhos raciais.

elas se fazem num incessante processo de negociação, alravés de variadas estratégias e alternativas, na defesa de sua condição multifacetada de ser negro no Brasil.

\section{O negro na Primeira República}

Salvador sai da escravidão e do Império sem grandes alleraçōes na ordem económica e social. E assim permanece durante toda a Primeira República. Não se constitui uma nova ordem burguesa, não apresenta grande crescimento demográfico' e inexistem expressivos contingentes imigratórios estrangeiros ${ }^{2}$. Os negros e mestiços - alé hoje - são majorilários em toda a sua existencia ${ }^{3}$.

A inclústria existente é uma atividade em involuçāo, com baixa capilalização, em grande dependência do setor mercanlil.

Quem manda na cconomia da cidade é o alto comércio de exportação de nossos produtos primirios, sobretudo o cacau, mas também o açúcar, o fumo, o sal, os couros; e o comercio grossista, importador de mercadorias de outros países ou estados brasileitos para atender às necessidades do consumo local.

Entrelanto, o poder político permanece como um atributo das oligarquias rurais, mesmo quando os seus represenlantes são citadinos ${ }^{4}$.

Sociedade estamental, onde as famílias tradicionais dos grandes proprielários, os comerciantes ricos, em grande parte de descendencia européia, os altos funcionários e políticos vão compor o núcleo central, o estamento dominanle. Exclusivamente formado por brancos e os raros mestiços que ali chegam consagram a regra embranquecendo-se.

No outro extremo da sociedade, o povo, em grande parte a massa trabalhadora, negra, a formar a "gentinha", a "arraia-miúda".

Entre os mesmos, um estamento intermediário que envolve os pequenos e médios comerciantes, os profissionais liberais, os funcionários públi-

1 Snlvador tinha em 1890, 174.412 habitanles; em 1900, 205.813 habilantes; em 1920, 283,422 habitantes; em 1940, 290.443 habilantes. Fonle: Sinopse essatistica do Brasil 1972. Rio de Janeiro: Fundaçto IBGE, 1972.

20 censo de 1920 registrn n presen ̧̧a de apenas 7.763 esirangeiros em Salvador. Fonte: Recentseamento do Brasil 1920. Rio de Janeiro: Directoria Geral de Estalistica, vol. IV, st parte, tomo 1.

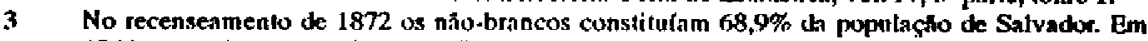
1940, segundo o Censo Demografico (Rio de Janeiro: IBGE, Serie Regional, volume XX, lomo 1, Estado لá Babia) os năo-brancos permaneciam com 66,2\% da populaç̧o da cidaute.

4 TEIXEIRA, Cid. As oligarquias na polftica baiana IN: LINS, Wilson el alii. Corontis e oligarquioss. Salvackot: UFBa, lathama, 1988, pp. 29-59. 
R. Htstörin, Stro Paulo, n. 129-131, p. 53-65, ngo-dez/93 a ngo.-tlez./94.

cos, os empregados no comércio, com muitos mestiços, identificados virlualmente pela lealdade e solidariedade aos grupos domimantes.

Existe mobilidade social $\mathrm{e} \mathrm{cm}$ geral a ascensĩo $\mathbb{E}$ possivel no proprio estamento, porém, torna-se quase impossivel penetrar no estamento superior. As distancias, hieraryuicamente definidas, são respaldadas pelas expectativas de Iratamento e de comportamento tradicionais cmanadas dos grupos dominanles. $1, \ldots+\cdots$

E são eles que estabelecem o poder privado, suplanlado ou confundindo-sc com a ordem pública, aparecendo as relaçóes pessoais como elementos bísicos na sedimentaçăo do poder, relaçóes onde desponta o favor e a concessão, em troca de subserviência e extensão desigual do poder, a caracterizar as hierarquias e os controles estathelecidos pelos "donos do poder"

Assim, nāo obstante o traballio livre, o trabalhador $\mathfrak{e}$ contralado não apenas por sua qualificaçĭo profissional ou capacidide de trabalho, mas sobretudo por sua condição pessoal, moral". Ele deve ser "obediente", moderado e de bons costumes".

As lormas de re muneraçāo sĩo sempre mistas - dinheiro, mais comida, casa, cmpréstimos, etc - a referendar o primado das relaçöes pessoais.

É esta sociedade que Donald Picrson chega a relembrar, por sua ordem c estabilidade, a Europa medieval (uma pena que não tenha visto os Senhores Feudais) ${ }^{7}$. E os grupos dominantes nĩo (puerem mudanças.

Ainda no calor das festas ou no sccar das lágrimas com a Aboliçāo, o Presidente da Província em 16 de maio já propōe a criação da Sociedade Treze de Maio - prontamente aceila -, a qual, excetuando a escola instalada e para formar os homens de "bons costumes" e que chega a abrigar 197 alunos - estabelece as seguinles prerrogativas:

1) quem define a remuneraçĩo ou forma de retribuição da força de Irabalho é o ex-Senhor;

2) o ex-escravo deve cumprir o'contrato (em geral verbal) com o seu empregador mesmo sendo uma simples reproduçĩo das relaçōes escravistas;

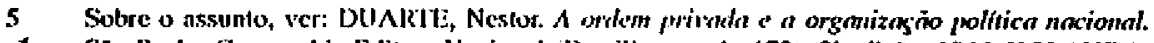
Sío Paulo: Companhia Edilora Nacional (Brasiliana, vol.. 172), 2" edição, 196o. ItOLANDA,

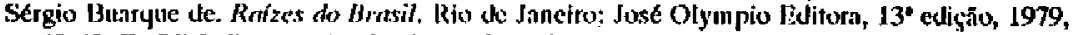

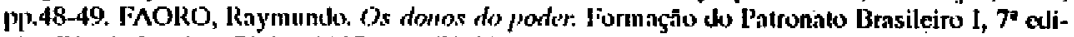
sîu, Rio de Jancito: Globo, 1987, pp. 171-201.

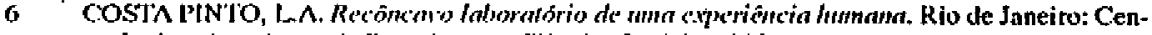
Iro Latino-Americano de l'esyatisas em Ciencins Suciais, 1958 , p. 112.

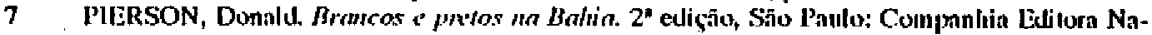
cional (Brasiliana, v. 241), 1971, p. 97. 
BACELAR, Jeferson .O negro em Salvalbr: os alathos mcinis.

3). caso não queira se sujejtar aos conlratos de Iraballıo, será enquadrado criminalmente como vagabundo, na vadiagem ${ }^{8}$.

A ordem social é mantida, sem maiorés alleraçōes, com a preservaçīo da ólica paternalista, a ordem privada definindo as relaçōes de trabalho e o apoio do poder público para o cxercício da conção.

Com a República, mais de um ano após a Aboliçāo, têm início mudan-, ças na esırulura de poder, com nítidas repercussōes na massa Irabalhadora. $A$ ampliação do direito de volo, propicia a multiplicidaide de facçōes partidárias, represenlantes dos interesses dos grupos dominantes. E serảo as lulas. entre os grupos dominantes que gerarão um clima de efervescencia polílica na cidade, com cada ùma das lendéncias parlidárias, lenlando formar bases. de apoio nos setores até cniāo exclúç̣os das dispulas".

Só que esta mobilização do "povo", nĩo obstante os desdobranıentos até mesmo inesperados, antes de propiciar a representatividade das calegorias subalternas, ela sedimenta as estruluras estabelecidas. O clientelismo político, uma extensão no âmbito público da ordem privada e das relações pessoais, divide a massa Irabalhatora, impossibilitando a constiluição, no, estrilo senso, de formas organizadas e aulonomas de participaçăo no mundo da política.

Evidencia-se, portanto, o controle e manipulação geral no âmbiło público, que se estende às relaçōes de trábalho, na medida cm que o texto constitucional de 1891 eslabelece o contralo como livre, cabendo apenas ao Estado assegurar o seu cumprimento:

Evidentemente, este amplo processo de dominaçĩo sobre a massa trabalhadora alingia os negros. Entrelanto, sendo cles maioria demográfica na cidade e entre os Irabalhadores, com exemplos assustadores de revoltas no passado, tornava-se fundamental para os grupos dominantes impedit a sua organização socielária.

Com a Abolição e a República, o racismo já é un componente "nalural" da sociedade, com suas prálicas discriminatórias inoculadas nả esı́rulura social, constiluído em princípio básico de sua estratificação. Se, com a Abolição, nada acontece em relaçĩo à questăo racial, com a República, modifica-se a situaçāo. A partir daquele momento, o negro teria direitos e

8 Falla com que o Exmo. Sr. Des. Aurélio Ferreirn Iispinheira 1" vice-Presidente dn Provincia, abriu a $2^{\circ}$ sessio th $27^{\circ}$ legislalura dh Assembléia Legislativa Provincial, no dia 3 de abril te 1889. Buhia: Typographia di Gazeta da Bahia, 1899, p 118.

9 SAMPAIO, Consueto Nuvais. O Poder Legislmivo da Bahia - Primeira Reptiblica (1889 1930). Salvautor: Assembléia Legislativa/UIFBn, 1985. 
R. Ilistórta, Sî́ Paulo, n. 129-131, p. 53-65, ago.-dez/93 a ago.ekz./94.

deveres como qualquer um perante a lei e a sociedade, devendo a sua condição de igual ser resguardada por todos, cabendo inclusive aos grupos dominantes proteger e sacralizar a sua nova siluação no mundo social. E isto é efelivado com propriedade e eficácia: indignando-se com a violência policial "contra um pobre velho", reagindo ao volo de Epitácio Pessoa na Conferência de Paris pela desigualdade das raças; incentivando protestos conıra a siluação racial americana; dizendo que racistas são os outros, os estrangeiros da cidade ${ }^{10}$. Começa a formular-se a democracia racial à brasileira.

Enırelanıo, no que tange ao cotidiano, à vivência de negros e brancos da e na cidade do Salvador, onde as condulas racistas estão internalizadas em todos os segmenlos da cidade, é elaborado um "pacto de silêncio". Em nenhum instante se discute a situação do negro no mercado de Irabalho, onde ocupa as posiçōes mais aviltadas, nem tampouco que thes é vedado o acesso a certas categorias profissionais nāo requerentes de maior qualificação profissional, como é o caso do trabalho como "caixeiro" nas principais lojas e casas comerciais da cidade. Não se Irala da segregação nos espaços públicos, expressamente delineada no ambito do lazer. Não se retratam as tormas desiguais de tratamento e relacionamento - com toda a cordialidade, cvidente, desde quando o negro se "assuntasse", ficasse no seu lugar" - entre negros e brancos.

Entretanto, diante desse quadro dramático de acomodaçāo, numa sociedade com esıratégias consolidadas de dominação, qual a situaçăo do negro e os mecanismos utilizados para a sua atïrmaçāo em Salvador?

De acordo com os dados sobre ocupaçäo dos cemitérios de Salvador em 1892 e os levantados por Donald Person em 1936, a tonica geral é uniforme, não obslante reflitam momentos hislóricos distintos. Em ambos o negro se insere nas categorias mais baixas da estratificação ocupacional e, de forma generalizada, em atividades em grande parte dependentes da força física ou com pequeno nível de especializaçīo.

Numa sociedade que os discriminava aberlamente na esırutura social e ocupacional, avocar a questīo racial seria uma afronta à ordem social que os considerava "iguais" com conseqüências incontrolâveis: 0 caminho seria outro.

Para o negro, como empregado, o roteiro seria a aceitação das formas variadas de sujeição, construindo inclusive a figura do "bom trabalhador". E muitos o fizeram, atingindo sob a proteção dos "donos do poder", uma certa estabilidade ocupacional e económica. Todavia, outros tantos rejeitaram tal postutado.

10 BACELAR, Jelerson. A presenకn espanhola ma Bahia. Os galegos no "paráso racial" 1900. 1950. Satvakur: Centro Editorial e Didtilico to UFBA., 1992. 
BACELAR, Jeferson .O negro em Silvadur: us atalhus raciais.

O caráter disciplinar e de subserviência dos padrōes vigentes nas relaçōes de trabalho conflitava com o desejo de autonomia do negro, com o exercfeio polílico de sua liberdade. E, aindá mais, ele sabia que muito pouco ganhava no tempo e esforço dedicálo ao I rabalho que produz riqueza para os oulros. Por sua vez, o negro já tinha a experiência de liberlos que, alravés do Iraballo autonomo, por conta própria, tinham conseguido ameallhar razoável património.

Nos quadros ocupacionais cilados, já se configura uma das estratégias essenciais do negro no mundo do traballıo: a inserção em atividades que possibilitavam o regime de trabalho aulonomo. No setor primário, no Irabalho nas roças e no mar, no setor secundairio nas allividades artesanais e nos olícios, no setor terciário, no comércio ambulante, no transporte de mercadorias e serviços doméslicos.

E serão nesıas alividales - vilais para a economia da cidade (o caso do transporte de mercadorias) ou da existência do eslamenlo superior (que nāo Irabalha) - que o negro imprimirá sua régua e seu compasso, criando seu próprio rítmo e tempo concedido à produçĩo. Evidentemente isto conflitava inteiramente com a lógicá disciplinar que os palrões, os senhores, gostariam que fosse imprimida ao trabalho. Pior, estendia-se para as fábricas, as casas comerciais e o serviço público.

Contra a eficácia, o atraso ou o absenteísmo; contra a produlividade, a clemora no fazer; conlra a submissão, a silenciosa aulonomiá comportamental.

A formulaçĩo polílica, a forma de resistência, sem confrontos, estabeleciua pelo negro perante o munclo do trabalho c dos brancos, ć ulilizada para the conferir mais um atribullo negalivo: a preguiçall.

E será do trabalho autónomo, conforme conslalamos no levanlamenlo que estamos realizando nos Inventários e Testamentos ${ }^{12}$ do período, que emergirá a possibilidade de acumulação de capilal e palrimônio, embora limilados, óbvio. Escusado e dizer o significado das mulleres negras na constituição das famílias e capitâis, por sua particcipaçāo no mundo do traba-

11 O esterestipo do "baiano preguiçuso" construf́to pxlas elites bajanas, é huje um dos argamentos da propensâo separatistin vigente no Sul do país. O psicúlogo Emir Calluf, Jisse que "apus 98

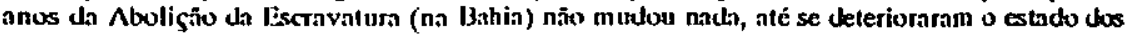
prelus, que prosseguem ma incklència, na orgia, na unalandragem e na simples tarefa animal de se reproxhuzirem". A Tarde. Leiturn e Informagio, 27/0\%/92, p. 7.

12 Imentários e Testamentos. Seçấo Judiciária. Arupuivo Püblico do Estacb te Bahia. De certa forma, referendamus a hipustese estabelecich por Maria Brandtio da relaçh̆o entre as condiçúes econômicas du negro nessa fase e a vitalidacle de sun cultura. BRANDĀO, Maria de Azevedo. "Conversa de branco; yuestóes e nîo-questôes du literaturn sobre rełaçūes maciais" IN: Retissa Vozes. O Negro e a abroliş̄ono. Sĩo Paulo, abril de 1979, nº 3. 
R. Histơrin, São Paulo, n. 129-131, p. 53-65, ago.-dez/93 a ago.-dez./94.

1ho. Porlanto, será do tempo e das economias advindas da "cultura do trabatho" que o negro manterá vivo na sociedade um campo simbólico, interativo e dinâmico.

Um mundo negro, nos candomblés, no carnaval, nas festas religiosas e profanas, na culinária, na medicina popular, uma cosmologia, formas de tratamento e solidariedade, samba e capoeira e a matrifocalidade familial.

Entrelanto, embora significativos na construçāo do "mundo negro", ao lempo livre e no dinheiro deve ser adicionado um clemento de reforço, essencial: a política cultural dos grupos dominantes.

O estamento superior buscou exasperadamente a identificaçâo com a cultura européia. Por mimetismo, pra não dizer "macaquice", eram copiadas modas e modos da Europa, para se dizer parte do ocidente avançado, inclusive afastando como modelo a nossa matriz básica, os portugueses. Evidentemente era uma cultura ornamental, "fora de lugar" inteiramente inadequada à lotalidade dos grupos que compunham a nossa socicdade. Enlrelanto, preciso que se alente que ela foi adolada não apenas peta dependência que possuímos em relação aos valores europeus, nem lampouco que ela viesse a se constiluir cm repertório comum da sociedade. A curopeização representava sobreludo a consagraçāo das distâncias sociais, via cultura. Evidentemente, isto significa que, desde quando os negros nāo quebrassem os padrōes vigentes comportamentais e não expusessem suas práticas abomináveis, poderiam no recondilo de seus espaços fazer o que quisessem. E is to permite, abre um grande espaço para a formulação autonómica de um mundo negro baiano, com raizes na África.

Um mundo cultural paralelo que ecoa pela cidade, forjado na luta pela sobrevivência, plasmado na resistência à discriminação e mesmo à repressão, com aparente acomodaçāo, negociaçāo è muitas vezes o silêncio.

\section{O negro na sociedade moderna}

A parlir da década de 50 e sobremodo nos anos 60 , assistimos a uma completa translormaçĩo da nossa sociedade, com nílidas repercussóes sobre a vida dos negros em Salvador.

A nova indusı rializaçẫo, uma exlensão do desenvolvimento indusıtrial do Sudoeste, iria provocar protundas mudanças na cidade e no seu espaço.

As moclernas empresas instaladas no Centro Industrial de Aratu e posteriormente no Complexo Petroquímico de Camaçari, com grande concentraçāo de capital e voltadas para a produçāo de bens intermediários, lornam-se o polo dinâmico da economia regional. 
BACELAR, leferson. O negro em Salvador: os atalbos raciais.

Com o desenvolvimento industrial, moderno, demandamente de superabundância de força de trabalho, transforma-se de forma radical a demografia da cidade, com o afluxo de grandes contingentes da zona rural.

Os modos alternativos de produção são esmagados - embora persistam pela nova industrializaçāo e serviços modernos - tornando-se o trabalho por conta própria, no máximo, um expediente de sobrevivência. Ressalte-se, cada vez mais utilizado.

O emprego já nāo pode ser rejeitado nem mantida a "cultura do trabạIho"; afinal, ja tinha muita gente para disputar as limitadas vagas.

Processa-se, por sua vez, a alteraçāo do traçado urbanístico, com significativa expansão da cidade e a "periferização" avassaladora, sem os mínimos requisitos em termos de serviços e habitabilidade para os contingentes pobres. A cidade é envolta èm um grande cinturão de pobreza.

A cidade estrutura-se em classes, com uma burguesia local identificada com interesses nacionais e internacionais; as classes médias e a nova classe operária (vinculada ao polo dinámico da economia) relacionadas com a perspectiva da ascensão social e econômica; e as classes trabalhadoras urbanas, näo incorporadas ao polo afluente da economia, nutridas por um sentimento e prática de pertencimento a um grupo de co-habitantes de uma regiāo social, ou seja, a condição de trabalhadores pobres.

A burguesia local é formada de brancos e mestiços claros; negros e mestiços aparecem nas classes médias e no novo operariado, entretanto, com os negros ocupando em geral os postos menos valorizados e, por sua vez, os negros são maioria entre os Irabalhadores urbanos ${ }^{13}$.

Portanto, na sociedade moderna de Salvador é mantida a discriminação racial sobre o negro, com a sua "periferização" espacial, económica e social, aguçada velozmente nesses "tempos coloridos de primeiro mundo". Todavia, a partir da introdução de novos focos dinámicos na economia da cidade, altera-se a formulação sobre as relaçōes raciais.

Os indivíduos são categorizados de acordo com as suas posiçōes face às relações de produção e participação no consumo, bem como, pela posição histórica dos diversos grupos a que pertencem no contexto da sociedade baiana. Objetivamente, para os grupos dominantes e as categorias sociais ascendentes, o ser negro permanece vinculado às posições mais baixas da sociedade e, por sua vez, identificados negativamente através de imagens, estereótipos, expressöes.

13 GUIMARÃes; Antonio Sérgio Alfredo. "Les classes el leurs couleurs à Bahia" IN: Cahiers d'Étudesafricanes, 125 XXXII - 1, 1992. 
R. Iltstórln, São Paulo, n. 129-131, p. 53-65, ago.-dez/93 a tígo.-dez./94.

Porém, ántes que contraditoriamente, de Corma articulada e legitimadora é reforçado o mito da democracia racial. A sua manulenção tem como base um antigo falor, dotado de nova função, ou scja, a expressividade numérica da população negra. Destarte, os negros se afiguram como elemenlos fundamentais à manutençāo e ao incremento das relaçōes capitalisıas de produção. Esłas, com seus "sulis" mecanismos de seleção no mercado de trabalho, não apresentam razóes que justifiquem manifesta discriminação. Correlacionado com este aspecto, atenta-se para o perigo que o acirramento da contenda racial poderń provocar no seio da sociedade baiana.

Os aparclhos idcológicos do eslado, em sua múltipla difusāo, enfalizam a igualuade das relaçôes entre indivíduos e grupos distintos, promovendo a imagem idealizada da sociedade baiana. Identificam-na como um modelo de convivência racial e de humanismo, fazendo a sua promoção a nível nacional e internacional.

Associada à democracia racial afirma-se a democracia cultural, possibilitando aos negros cultivar a sua herança africana. A celebraçāo, a exaltação da África e do negro esırangeiro, tão ao gosto dá intelectualidade baiana, enfatizam, como contraponto, a igualdade cullural enıre as raças em Salvador. Quais os mocanismos, nesse novo momento histórico, para a afirmação do ser negro em Salvador?

Tentativas foram elcluadas no campo político $\mathrm{c}$ todas as candidaturas que se pautaram em um discurso de natureza racial, redundaram em fracasso. A sua parlicipação, na condição de negro, no novo movimento sindical, esbarra no corporativismo orientado para melhores salários e privilégios para os trabalhadores organizados.

O próprio movimento negro, por ser composto de um setor que ascendeu socialmente e perspectiva intelectualizante, nāo atrai a massa negra pobre e em grande parte analfabeta. Mais ainda, a visão polarizada do movimento em relaçāo à situação racial baiana - negros e brancos -, além de uma postura radical de aluação, implica na redução da identidade social à raça, o que afası muitos negros das suas práticas e vivências cotidianas.

Os movimentos sociais urbanos, por sua vez, vinculados a reivindicaçōes para a satisfaçāo de suas necessidades imediatas c básicas de sobrevivência, têm no problema racial uma questâo secundária.

Assim, conforme podemos observar, os espaços cslavam - e permanecem - fechados para a afirmaçāo do ser negro. Entretanto algo ficara vivo, linha bases firmes, atravessara a escravidão, vencera a reação por mais de $\mathbf{4 0}$ anos e mesmo com as "novas tecnologias" eslava aí: a hisı́ria vivida e conlada no seu imaginário social, em grande parte plasmada na cultura, tendo como eixo central o candomblé. 
BACEL_AR, Jeferson .O negro em Silvador: as atal bus racinis.

Desta forma, a partir le 1970 , os negros elaboraram uma nova proposlil para o carnaval, revivendo de forma contemporânea os anligos afoxés. Assim, nasce o Ilê-Aiyé, como uma forma de reação ao carnaval-branco e com uma proposla de celebrar os valores da cullura negra nacional e internacional. Aparece num grande bairro de traballadores urbanos, a LIBERDADE, com uma populaçāo com enorme contingente de negros, "Iendo o candomblé nas suas porias".

O sentido de pertencer dos traballadores urbanos negros plasmado na regiäo ganha o componente racial, alravés do novo bluco.

A cultura torna-se ideologia e política na construçĩo da identidade social do negro em Salvador. O seu poder de atraçĩo é enorme, pela aproximação com a vivência colidiana dos segmentos negros. De forma dinâmica, as raízes africanas inventadas são revividas nas Irancinhas, mas argolas, nas roupas, nas músicas, criando um sentimento de negrilucle, com um referencial identificador.

A parlir do Ilé, criam-se outros afoxés e blocos-afros na cidade, com as suas variaçóes, mas manlendo a perspecliva da negritude.

É na década de 80 , porém, que se afirma a sua primazia entre os negros, com vertiginosa expansão na cidade. A afirmação da negrilude espaIhou-se por todo o corpo social. A vaidade e o orgulho de ser negro, bem como a criação de delerminados "espaços de negros", como a Liberdade e o Pclourinho, "invadem" a cidade do Salvador.

Em sua maioria jovens, eles eslavam juntos, linham força, capacidade de identificar-se como grupo. Já não precisavam alaslar-se de sua cor, já possuíam os seus espaços, já admiliam a possibilidade do exercício da cidadania como negro.

Entretanto, além destes aspectos singulares, extremamentc posilivos da cultura na afirmação do ser negro em Salvador, torna-se indispensável ver o outro lado da história.

Ao contrário do passado, a produção cullural no capilalismo lendo como eixo a economia, atende a uma lógica expansionista e padronizadora, com uma definida nalureza política.

A cultura dos grupos doninantes, assion, nāo apenas mantém a supremacia, mas alravessa lodo o corpo social buscando o seu direcionamento e controle. A sua autoridade c capacidade de disseminação - gostos, estilos de vida, modas, valores - é reiterada por intermédio de medidas estatais do próprio governo, que procura conırolar o mercado de bens simbólicos.

Se, no passado, na primeira lase, nāo podemos esquecer o papel impositivo da cultura dos grupos dominantes em relaçāo aos grupos subalternos, agora, ela aparece como elemento tolalizador e coercitivo. 
R. Hlstórta, Såo Paulo, n. 129-131, p. 53-65, ago.-dez/93 a ngo.-dez./94.

Porém, o caráter da dominação não implica necessariamente, e isto é flagrante no caso dos negros baianos, na ausência de criatividade nas culturas populares. Vale ressaltar, que as gritantes desigualdades e discriminaçōes em relação aos grupos em Salvador, lorna a sua cultura, sobretudo pelas raízes e bases firmes na sua vivência, uma espécie de "resposta" à maneira de ser dos brancos. Relacionada e participando de um conjunto de que constitui parte integrante, reforça-se a cultura negra sob o prisma do contrasle, como modo alternativo a sua experiência social.

Deslocado torna a discutir questōes como "autenlicidade", "pureza", "originalidade"; o que importa é entender como os elementos culturais advindos de oulras matrizes e grupos, se incorporam à realidade do negro e a seus valores. Por exemplo, enquanto nas primeiras décadas da nossa República as camadas superiores eram as virluais importadoras de traços estrangeiros, hoje, pela enorme expansāo dos meios de comunicação, as influências exteriores penetram a fundo nas categorias subordinadas, entre os negros. $O$ fundamental a se compreender é que estes elementos - latinos, americanos, africanos - se incorporam e "funcionam" adequadamenle na cultura dos negros da Bahia.

Em Salvador, diante da expansão criativa dos negros, os grupos dominantes apropriam-se do seu referencial, atribuindo-lhe novo sentido. Os intelectuais são substituídos pelas novas formas de disseminaçāo da cultura, a mídia, na mercantilização do exótico, do diferente. A produção cultural dos negros, sobremodo a música e a dança sāo transformadas em "retrato da baianidade" e inseridas no circuito capitalista de consumo de bens simbólicos transmulados em mercadorias.

O ano de 1993 foi a consagração nacional e internacional do carnaval baiano, com os diversos canais da mídia explorando a sociedade diferente, exótica, a "axé-music", a "limbalada" e o "canto da cidade" de sua musa - "a branca mais neguinha da Bahia" como ela própria se intitulou na televisão Daniela Mercury.

Definindo o carnaval como um produto basicamenle negro, alicerçouse a perspectiva da festa iqualitária, a expressão extraordinária da democracia racial e cultural.

Na realidade, a valorizaçāo mítica, romantizada da cullura negra como produto, tem alingido vários propósilos, entre outros, a segregação racial e a ausência de alteraçōes na posição dos negros na estrutura de classes.

No carnaval de Salvador, ao contrário da leitura do mundo diário de nossas vidas onde somos desde a década de 30 , livres e iguais, se estrulura um sistema allamente preocupado com as gradaçōes e hierarquias.

A própria organizaçāo oficial do desfile pauta-se em linhas marcantes de distinção social arliculadas com o critério racial na formação de grupos: 
BACELAR, Jeferson. O negro em Salvador: os atalhos raciais.

de um lado, "os blocos de trios" (popularmente conhecidos como blocos de "barões", de "brancos"); do outro, os blocos dos pobres e negros, ou seja, os afoxés, os blocos-afro, os blocos de índios, etc. Sāo estabelecidas gradaçōes sociais internas na estruturação de cada grupo e formas separadas de participação na composiçảo global do desfile.

Todos juntos no maior carnaval - participação do mundo, mas efelivamente "cada qual no seu cada qual". Inexiste interação societária entre os grupos, sendo as cordas o marco físico de cada fronteira. Diante da afirmação do negro no carnaval, por sua vez, as classes média e alta, auto-identificadas como brancas, reagem estabelecendo critérios rígidos de discriminação social e racial para a participação nas suas organizaçōes. Quanto mais os valores negros ganham dimensão no carnaval, mais são sedimentadas as marcas dislintivas, que envolvem desde a condição fenotípica, posição econômica, rede de relações, hábitos e comportamento, local de moradia, para a inserção no "grupo dos brancos". Para alicerçar ainda mais as fronteiras procuram dar realce ao sentido de "segurança intramuros", pela distingüivel barricada de proteção (nas cordas)... de negros.

Dirfamos, enquanto o negro afirma a sua negritude, o branco não quer "mistura". Enfim, no carnaval exterioriza-se, de forma pungente, a posiçäo dos negros na hierarquia social $e$, por sua vez, temos a expressão marcante da construçāo dos "muros brancos", com grupos identificados social e racialmente.

A festa, o carnaval segundo nossa concepção, não é um momento extraordinário, mas a exacerbação do ordinário que torna visível o destino de nossa sociedade. A "cara do negro na tcla" e a apropriação de espaços ressalle-se, desvalorizados socialmente - consagrados à celebração do mundo negro, tem gerado como resposia, "com loda cordialiuade", por parte dos brancos, a perspectiva da "homogeneidade racial", no espaço e no mundo social. E uma realidade, a presença de condomínios e areas residenciais isoladas da "impureza" advinda da sociedade envolvente e, por sua vez, a separaçāo nos ambientes sociais, nos restaurantes, praias e outras formas de convivencia. Não estaríamos caminhando para um "apartheid à baiana"?

Por sua vez, a transformação da cultura negra em produto da indúsıtria cultural tem um grande impacto sobre os negros. Ela desenvolve a seleção, a escolha de grupos e indivfduos para a inserçâo e ascensão no mundo artístico e cultural, gerando cisões e dispulas na comunidade negra em função do acesso ao mercado capitalista de bens simbólicos. O status, o prestígio de individuos e blocos começa a ser mensurado pela sua aceitação, pelo estágio de cooptação no mundo dos dominantes.

Entretanto, um problema mais grave emerge do alual momento baiano, ou seja, a perspectiva entre os negros da supervalorização da limitada econo- 
mia que nasce da cultura, confundindo-a com a participaçāo do negro no mercado de Irabalho. A questão é que, além da escassa participação đa força de trabalho no mundo cultural, verifica-se a reafirmação e consagraçāo das características "naturais" do negro. Reiteram-se, a nívél dos grupos dominantes, a estigmatização e a tentativa de sacralizá-lo como homem incapaz de razão e elemento justificador da sua não-mobilidade e ascensão na sociedade e no mundo do trabalho.

Portanto, a cultura é vida e perigo, força e tentaçāo, porém, quem conheceu a Salvador dos anos 50 e 60, quando o "negro estava em seu lugar", sabe os avanços que ela proporcionou e o significado de poder dizer-se negro. Ela foi, e é, o atalho do negro na construção da sua condição racial em Salvador. Como eu disse em outro trabalho, o que virá, só Deus o sabe, aliás Ogum, mas temos a certeza, muitos já abriram os caminhos para não aceitar a cozinha e o quarto dos fundos.

ABSTRACT: The author studies the black popalation in the city of Salvador since the first decales of the $20 \mathrm{th}$ century until the present days, emphasizing the regional viewpoint of prejudice and racial discrimination. The power structure and methods of control established by the dominam social group outline the study of racism.

The black person is analyzed through the binomial action-reaction, that is: as victim and as an active social agent inserted in the dynamics of modern society. Culture is illustrated in sach a way as to demonstrate its ideological and political interference in the formation of a social identity of the blact in Salvaitor.

KEY-WORDS: Carnival, racism, social control, identity, resistance. 